\title{
Acute intravascular haemolysis associated with cephalexin therapy
}

\author{
Charles D. Forbes \\ M.B., Ch.B., M.R.C.P. \\ RUTHVEN MitCHELL \\ B.Sc., M.B., Ch.B., M.R.C.Path.
Deputy Director, Regional Blood Transfusion
Centre, Law Hospital, Carluke

\author{
James A. Craig \\ B.Sc., M.B., Ch.B. \\ George P. McNicol \\ M.D., Ph.D., M.R.C.Path., F.R.C.P.(Glas., Edin.) \\ Regional Haemophilia Centre, University \\ Department of Medicine, Glasgow Royal Infirmary
}

Cephalexin, a now semi-synthetic antibiotic derived from cephalosporin $\mathrm{C}$, has the same basic nucleus and the same range of activity as its predecessors, cephalothin and cephaloridine but has the advantage that it can be given orally. As this drug is relatively new, few side-effects have been described.

The following case report is of a boy, aged 14 years, who developed acute intravascular haemolysis while taking cephalexin.

\section{Case history}

The patient was a severely affected haemophiliac with no antihaemophilic factor (AHF) activity detectable in his plasma. He sustained a rupture of the ureter, multiple fractures of ribs and large haematomata of head, arms and legs, as the result of a crushing injury. This was associated with intraperitoneal bleeding and a fall in haemoglobin from 15 to $6 \cdot 2 / 100$ $\mathrm{ml}$. Surgery to the ureter was undertaken under cover of cryoglobulin precipitate, a potent concentrate of antihaemophilic factor prepared by cold precipitation of human plasma (Pool, Hershgold \& Pappenhagen, 1964). Four units of donor blood were transfused to bring the haemoglobin to $12 \mathrm{~g} / 100 \mathrm{ml}$. No serological abnormalities were detected at the time of performing the matching tests. The infusions of cryoprecipitate were continued for 32 days to allow complete healing of the ureter, skin incision and the drainage tube tracks. On the sixth postoperative day the patient developed haematuria and a haematoma of the thigh at the site of an intramuscular injection when the AHF activity of the plasma fell below the haemostatic level. This was the only time the patient had any evidence of bleeding during the postoperative period.

During anaesthesia the patient aspirated gastric content and developed a pneumonitis of the left lower lobe and collapse of the right upper lobe. This was treated with ampicillin, $1 \mathrm{~g} /$ day for 9 days, then with cephalexin, $2 \mathrm{~g}$ /day for 13 days (Fig. 1).

Blood urea was elevated to $50 \mathrm{mg} / 100 \mathrm{ml} \mathrm{im}$ mediately after surgery but rapidly fell to normal and

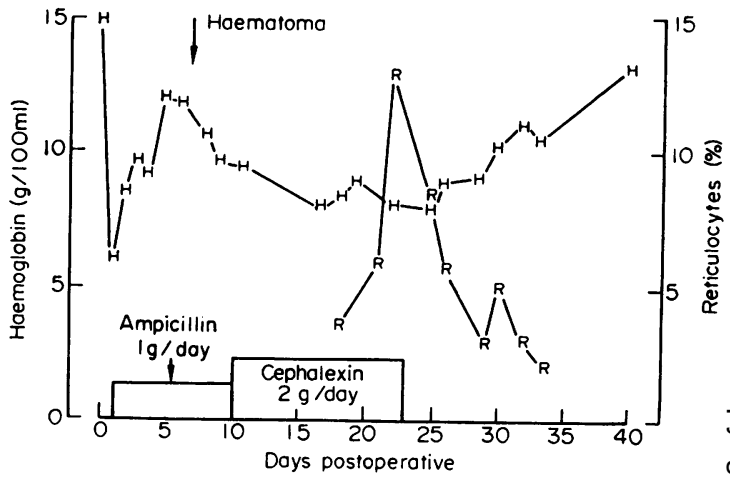

FIG. 1. Postoperative course of the patient showing the relation of antibiotic therapy to haemoglobin levels (H) and the reticulocyte count (R).

at the time cephalexin was administered ranged from $20-25 \mathrm{mg} / 100 \mathrm{ml}$.

Nine days after the start of cephalexin therapy the patient's plasma was noted to be brown in colour and the following results suggestive of acute intravascular haemolysis were obtained; methaemalbumin $2.34 \mathrm{mg} / 100 \mathrm{ml}$, plasma haemoglobin 6 $\mathrm{mg} / 100 \mathrm{ml}$, reticulocyte count $5 \%$, total bilirubin $1.6 \mathrm{mg} / 100 \mathrm{ml}$. Direct broad spectrum antihuman globulin (Coombs') test using a standard slide technique was negative and the osmotic fragility of the red blood cells was normal. Haemolysis increased and maximum values were seen on the thirteenth day of cephalexin therapy when the reticulocyte count was $13 \%$, the methaemalbumin $3.47 \mathrm{mg} / 100 \mathrm{ml}$ and the plasma haemoglobin $8.9 \mathrm{mg} / 100 \mathrm{ml}$. The serum level of cephalexin obtained during this time was of $10 \mu \mathrm{g} / \mathrm{ml}, 3 \mathrm{hr}$ after an oral dose of $500 \mathrm{mg}$ and this occurred on the twenty-third postoperative day. Serum proteins were slightly elevated, the total being $8.7 \mathrm{~g} / 100 \mathrm{ml}$ with an albumin of $4.6 \mathrm{~g} / 100 \mathrm{ml}(55 \%)$ and globulin of $4 \cdot 1 \mathrm{~g} / 100 \mathrm{ml}(45 \%)$. Electrophoresis of plasma proteins showed elevation of the gammaglobulin fraction to $2.4 \mathrm{~g} / 100 \mathrm{ml}(25 \cdot 4 \%)$. complement level was normal. The maximum serum 
$\beta$-globulin $8.5 \%, \alpha_{1}$-globulin $8 \%$ and $\alpha_{2}$-globulin $3.1 \%$ were within normal limits. Plasma fibrinogen was grossly elevated at $1067 \mathrm{mg} / 100 \mathrm{ml}$.

Since it is reported (Kosakai \& Miyakawa, 1970) that the direct antiglobulin test on the red blood cells of patients receiving cephalosporins varies, depending upon the particular drug given and the particular antihuman globulin reagents and technique employed, it was decided to attempt to enhance the sensitivity of the method by using a two-stage method modified from that of Cohen \& Nelken (1964). The patient's thrice washed red blood corpuscles collected soon after cessation of cephalexin therapy were incubated at room temperature with goat antihuman serum, washed to remove free serum and followed by a rabbit antigoat serum on a slide. Careful attention was given to finding the optimal dilutions for the rabbit antigoat and goat antihuman sera. The patient's cells tested by this technique gave a positive reaction, control sensitized and unsensitized cells reacting satisfactorily. No irregular blood group antibodies were detected in the patient's serum. Direct antiglobulin reactions were performed using specific goat antihuman IgG immunoglobulin and anti- $\beta_{1} C$ component of complement with negative results. This is in agreement with Molthan, Reidenberg \& Eichman, 1967, who reported the coating on the cells of their patients to be nonspecific protein in nature.

Cephalexin was stopped at this time and thereafter the levels of plasma haemoglobin, methaemalbumin and the reticulocyte count fell and haemoglobin level rose to normal.

\section{Discussion}

All members of the cephalosporin group of drugs are known to bind normal plasma proteins to red cells in vitro and so produce a positive direct antiglobulin test (Kosakai \& Miyakawa, 1970; Mine et $a l ., 1970)$. The antiglobulin reaction is dependent on the type of antiserum used and in in vitro experiments the incidence of positive tests rises with the concentration of the drug.

Molthan et al. (1967) reported positive direct Coombs' tests in $75 \%$ of patients receiving cephalothin. This finding was confirmed by Gralnick, Wright \& McGinniss (1967) who showed that $40 \%$ of patients on cephalothin developed a positive Coombs' test. In these series, patients with impaired renal function had a high incidence of positive tests probably because of the high blood cephalothin concentrations and because azotaemic red cells were more easily sensitized. The incidence of positive tests was also higher in patients with hypoalbuminaemia.

A similar result was reported by York \& Landes (1968) and Foord (1970) in patients receiving cephaloridine. In the latter study involving sixty-five patients, the overall incidence of positive Coombs' tests was $15 \%$ but all the positive tests occurred in the group of patients receiving over $4 \mathrm{~g}$ of cephaloridine/day. This gave an incidence of $26 \%$ in this group. Perkins, Saslaw \& Billmaier (1967) reported similar observations in patients receiving cephalothin or cephaloridine. Girdwood (1971) reviewing the notifications to the Safety of Drugs Committee cites eight examples.

At least five cases of positive Coombs' tests have been recorded after cephalexin therapy. Two cases are quoted by Foord (1970), one of these being in a monkey and one case by Fass, Perkins \& Saslaw (1970). Also Erikssen. Midvedt \& Bergan (1970) report that two out of five patients on cephalexin developed a positive Coombs' test as determined by a 'tube' technique although the slide test was negative.

Positive Coombs' tests in patients on cephalosporins have been regarded as laboratory curiosities and of no significance with regard to haemolytic anaemia, however, two cases of acute haemolysis have been described (Kaplan, Reisberg \& Weinstein 1968; Foord 1971). The first patient received cephaloridine, and the second cephalexin. Both patients had however received penicillin therapy prior to the cephalosporin and both had impaired renal function. The incidence of cross-sensitization reactions between penicillin and cephalosporins is probably between 10 and $15 \%$ (Ky et al., 1970), but varies widely according to the criteria chosen.

The case presented here is complicated by the prior administration of ampicillin, the elevation of the gamma-globulin and the high fibrinogen level, but renal function, plasma albumin and the plasma level of cephalexin were all within normal limits. During the whole of this haemolytic episode and for 10 days thereafter, the patient received cryoglobulin precipitate and had no evidence of bleeding. Withdrawal of the cephalexin was associated with cessation of haemolysis.

The evidence available suggests that in this instance, despite the low dosage, cephalexin therapy resulted in acute intravascular haemolysis.

\section{Acknowledgments}

We wish to acknowledge the excellent team work of the physicians, surgeons and nursing staff of the Southern General Hospital and the Glasgow Royal Infirmary and the technicians of the Blood Transfusion Service by whose effort this patient made a complete recovery.

\section{References}

Cohen, I. \& Nelken, D. (1964) A two-stage antiglobulin test for the detection of ABO haemolytic disease of the newborn. Transfusion, 4, 343.

Erikssen, J., Midvedt, T. \& Bergan, T. (1970) Treatment of urinary tract infections with cephalexin. Scandinavian Journal of Infectious Diseases, 2, 53. 
Fass, R.J., Perkins, R.L. \& Saslaw, S. (1970) Cephalexina new oral cephalosporin: clinical evaluation in sixty-three patients. American Journal of Medical Sciences, 259, 187.

Foord, R.D. (1970) Quoted in Postgraduate Medical Journal, Oct. Suppl. 46, 108.

FooRD, R.D. (1971) Personal communication.

GiRDwOoD, R.H. (1971) The effect of drugs on the blood. In: Symposium on the Adverse Effects of Drugs (Ed. by G. C. Hanson). Beecham Research Laboratories Publication.

Gralnick, H.R., WRIGHT, L.D. \& MCGINNISS, M.H. (1967) Coombs' positive reactions associated with sodium cephalothin therapy. Journal of the American Medical Association, 199, 725.

Kaplan, K., Reisberg, B. \& Weinstein, L. (1968) Cephaloridine. Studies of therapeutic activity and untoward effects. Archives of Internal Medicine, 121, 17.

Kosakai, N. \& Miyakawa, C. (1970) Fundamental studies on the positive Coombs' tests due to cephalosporins. Postgraduate Medical Journal, Oct. Suppl. 46, 107.
Ky, N.T., Chauvin, M.T., Pinon, C. \& Halpern, B.N. (1970) Positive immunological reactions to cephaloridine in patients allergic to penicillin: a study performed with the lymphoblastic transformation test. Postgraduate Medical Journal, Oct. Suppl. 46, 109.

Mine, Y., Nishida, M., Goto, S., Kuwahara, S. (1970) Studies on direct Coombs' reaction by cefazolin in vitro. Journal of Antibiotics, 23, 575.

Molthan, L., Reidenberg, M.M. \& Eichman, M.F. (1967) Positive direct Coombs' tests due to cephalothin. New England Journal of Medicine, 277, 123.

Perkins, R.L., Saslaw, S. \& Billmaier, D. (1967) Coombs' reactivity after cephalothin or cephaloridine. Clinical Research, 15, 426.

Pool, J.G., Hershgold, E.J. \& Pappenhagen, A.R. (1964) High potency antihaemophilic factor prepared from cryoglobulin precipitate. Nature, 203, 312.

YORK, P.S. \& LANDES, R. (1968) Coombs' positive reactions associated with cephaloridine therapy. Journal of the American Medical Association, 206, 1086.

Postgraduate Medical Journal (March 1972) 48, 188-191.

\title{
An unusual case of acrodystrophic neuropathy
}

\author{
R. C. Hilton \\ M.B., M.R.C.P., D.C.H. \\ Manchester Royal Infirmary
}

THIS rare condition is characterized by progressive loss of sensation which usually occurs first and is most severe in the lower limbs, but may eventually become widespread. Thévenard (1953) reviewed 100 cases reported up to that time and since then others have been reported by Ogden, Robert \& Carmichael (1959); Pallis \& Schneeweise (1962); Walker (1955); and Spillane \& Wells (1969). It may occur as a familial disease, when it is often transmitted as an autosomal dominant character but other forms of inheritance can occur (Denny-Brown, 1951).

The familial form is characterized by recurrent, painless ulcers starting on the feet, usually in early adult life, with ultimate severe destruction of the feet and often of the lower legs. Sensation is usually first affected in the territory of one first sacral root, and in the earlier stages there is dissociated sensory loss, temperature sensibility being more extensively and severely impaired than pain, which is in turn lost more than touch. As more adjacent roots become involved this dissociation becomes less marked.

Sporadic cases also occur and it has been suggested that in these there tends to be a more widespread involvement of the sensory roots, an earlier onset of ulceration of the feet and lack of progression of the sensory neuropathy (Ogden, Robert \& Carmichael, 1959). Nerve deafness and lightning pains in the limbs may occur in either form.
The essential pathological change appears to be degeneration of the cells in the posterior root ganglia, and of their fibres both distal and proximal to the ganglia (Denny-Brown, 1951). The anterior roots are not involved; neither does there appear to be any primary involvement of muscle.

The cause is unknown and Denny-Brown (1951) has suggested that this may represent one end of a spectrum of conditions affecting nerve roots, the analogous disease of the anterior roots being the classical radicular form of peroneal muscular atrophy.

The patient here reported, a single woman now aged 60 years, presented with unusually extensive sensory loss and some other features of interest.

\section{Case history}

The details of this patient's early history are vague, but it is known that although her hands and feet appeared normal at birth she did not walk until the age of 3, and then only with difficulty. She later developed ulcers on the plantar and dorsal aspects of the feet, and the feet gradually became deformed, requiring an operation at about the age of 16 years. At a later date bone was discharged spontaneously from both feet. By the age of $\mathbf{3 0}$ she was unable to stand or walk. She has noted shooting pains in the upper limbs and repeated infections of the fingers over many years, and at the age of 50 her right index 